Analytical Methods

\title{
Sensitive and selective electrochemical detection of bisphenol A based on SBA-15 like Cu-PMO modified glassy carbon electrode
}

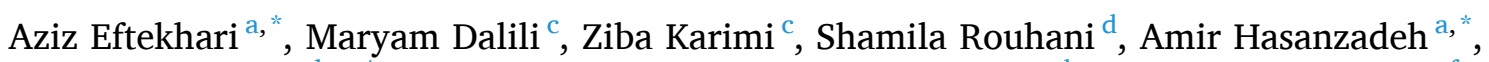

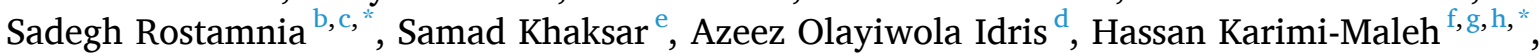 \\ Mehmet Lütfi Yola ${ }^{i}$, Titus A.M. Msagati ${ }^{d}$ \\ ${ }^{a}$ Maragheh University of Medical Sciences, PO Box: 78151-55158, Maragheh, Iran \\ ${ }^{\mathrm{b}}$ Organic and Nano Group (ONG), Department of Chemistry, Iran University of Science and Technology (IUST), PO Box 16846-13114, Tehran, Iran \\ c Organic and Nano Group (ONG), Department of Chemistry, Faculty of Science, University of Maragheh, PO BOX 55181-83111, Maragheh, Iran \\ ${ }^{\mathrm{d}}$ Institute for Nanotechnology and Water Sustainability (iNanoWS), College of Science, Engineering and Technology, University of South Africa, Johannesburg 1709, \\ South Africa \\ ${ }^{\mathrm{e}}$ School of Science and Technology, The University of Georgia, Tbilisi, Georgia \\ ${ }^{\mathrm{f}}$ School of Resources and Environment, University of Electronic Science and Technology of China, P.O. Box 611731, Xiyuan Ave, Chengdu, PR China \\ ${ }^{g}$ Department of Chemical Engineering, Quchan University of Technology, Quchan 9477177870, Iran \\ h Department of Chemical Sciences, University of Johannesburg, P.O. Box 17011, Doornfontein Campus, 2028 Johannesburg, South Africa \\ ${ }^{i}$ Hasan Kalyoncu University, Faculty of Health Sciences, Department of Nutrition and Dietetics, Gaziantep, Turkey
}

\section{A R T I C L E I N F O}

\section{Keywords:}

Sensor

Bisphenol A

Periodic mesoporous organosilica (PMO)

Glassy carbon electrode

\begin{abstract}
A B S T R A C T
This work reports the electrochemical detection of bisphenol A (BPA) using a novel and sensitive electrochemical sensor based on the $\mathrm{Cu}$ functionalized SBA-15 like periodic mesoporous organosilica-ionic liquid composite modified glassy carbon electrode (Cu@TU-PMO/IL/GCE). The structural morphology of Cu@TU-PMO is characterized by X-ray powder diffraction (XRD), energy dispersive X-ray analysis (EDX), Fourier transform infrared spectroscopy (FT-IR), transmission electron microscopy (TEM), Field emission scanning electron microscopy (FESEM), and Brunauer-Emmett-Teller (BET). The catalytic activity of the modified electrode toward oxidation of BPA was interrogated with cyclic voltammetry (CV) and differential pulse voltammetry (DPV) in phosphate buffer solution ( $\mathrm{pH}$ 7.0) using the fabricated sensor. The electrochemical detection of the analyte was carried out at a neutral $\mathrm{pH}$ and the scan rate studies revealed that the sensor was stable. Under the optimal conditions, a linear range from 5.0 nM to $2.0 \mu \mathrm{M}$ and 4.0 to $500 \mu \mathrm{M}$ for detecting BPA was observed with a detection limit of $1.5 \mathrm{nM}(\mathrm{S} / \mathrm{N}=3)$. The sensor was applied to detect BPA in tap and seawater samples, and the accuracy of the results was validated by high-performance liquid chromatography (HPLC). The proposed method provides a powerful tool for the rapid and sensitive detection of BPA in environmental samples.
\end{abstract}

\section{Introduction}

Endocrine-disrupting compounds (EDCs) affect the endocrine system in animals and humans by mimicking the biological activity of the natural hormones, occupy the hormonal receptors, interfere with the transport and metabolic processes of a natural hormone (Hengstler et al., 2011; Vandenberg, Maffini, Sonnenschein, Rubin, \& Soto, 2009). These effects have drawn the attention of scientists, research communities, and public awareness.

One of the essential industrial EDCs that have gained vast interest is bisphenol A (BPA). Bisphenol A (2,2-bis (4-hydroxyphenyl) propane) is a synthetic compound widely employed in the polymer industry as a precursor in the production of polysolfune resin, epoxy resins, and polycarbonates plastics. These plastics are used in the food and drink packaging applications, including plastic beverage containers, baby bottles, water, and milk bottles. Unfortunately, these plastics are disposed of into the environment and are accumulated in various water bodies (Apodaca, Pernites, Ponnapati, Del Mundo, \& Advincula, 2011; Geens et al., 2012; Hengstler et al., 2011; Vandenberg et al., 2009).

In recent studies, BPA was reported to be responsible for the

\footnotetext{
* Corresponding authors.

E-mail addresses: aeftekhari@mrgums.ac.ir (A. Eftekhari), a.hasanzadeh@mrgums.ac.ir (A. Hasanzadeh), rostamnia@iust.ac.ir (S. Rostamnia), hassan@uestc.edu. cn (H. Karimi-Maleh).
} 
endocrine disorder, threatening the health of pregnant women, foetus, and children (Chen et al., 2017; Rosenfeld, 2017). Hence, due to this report, it is imperative to develop rapid and reliable methods with high accuracy and precision for the determination of bisphenol A. Conventionally, various methods such as fluorimetry (Kim, Jeon, \& Chang, 2012), chromatographic techniques coupled with mass spectrometry (Chang, Chou, \& Lee, 2005; Nerín, Philo, Salafranca, \& Castle, 2002), enzyme-linked immunosorbent assay (Maiolini et al., 2014) and chemiluminescence (Ragavan \& Rastogi, 2016) have been employed for the detection of BPA. However, application most of these techniques is restricted due to the number of disadvantages such as expensive and complicated instruments, advanced technical expertise and timeconsuming (Duan et al., 2018).

The electrochemical techniques have recently become more admissible and attractive due to their fast response, high sensitivity, low-cost, and in-situ monitoring (Darabi \& Shabani-Nooshabadi, 2021; KarimiMaleh et al., 2021b; Tahernejad-Javazmi, Shabani-Nooshabadi, \& Karimi-Maleh, 2019; Tian et al., 2018). Since the direct determination of BPA using bare electrode provide low selectivity and sensitivity owing to the fouling effect and BPA overoxidation (Murugananthan, Yoshihara, Rakuma, \& Shirakashi, 2008); several efforts have been devoted to modifying electrodes with various materials such as nanoparticles, graphene and carbon nanotubes (Ben Messaoud, Ghica, Dridi, Ben Ali, \& Brett, 2017; Karimi-Maleh et al., 2021a; Krishnendu, Sarit, Chaekyu, Xiaoning, \& Vincent, 2014; Xin, Sun, Li, Wang, \& Jia, 2015). Nevertheless, some satisfying results have been obtained, however, development of a more efficient and straightforward electrochemical sensors for the detection of BPA remains major challenge in nano-electrochemistry.

The electrodes modified with periodic mesoporous organosilica (PMO) show high sensitivity owing to their large surface area and tunable pore structure (Wu et al., 2019). PMO with unique nanostructure and properties have recently received a great deal of attention due to easy modification of frameworks without pore blocking, highly ordered structure, extraordinary hydrothermal and mechanical stability, high specific surface area and pore volume. These properties help obtain many active sites and permit diffusion and adsorption of large molecules on the PMO surface (Esquivel, Van Der Voort, \& Romero-Salguero, 2014). These remarkable features make them a promising material in wide range of application including catalysis (Moaser et al., 2020), membranes and separation platform (Samiey, Cheng, \& Wu, 2014), drug delivery system (Esquivel et al., 2014), water treatment and sensor (Chandra, Das, \& Bhaumik, 2010; Morante-Zarcero, Pérez-Quintanilla, \& Sierra, 2015).

Ionic liquid (IL) has unique performances including good thermal and chemical stability, high ionic conductivity and stable electrochemical windows, which has been acted as supporting electrolyte or modifier of the working electrodes in electroanalysis. The electrodes constructed with these materials present a higher and high rate of electron transfer along with increased sensitivity and stability of the measurements.

Herein, we report the synthesis of thiourea based PMO (TU/PMO) using 1,3-bis(3-(triethoxysilyl)propyl) thiourea (bis-thiourea) and $\mathrm{Cu}^{2+}$ species was successfully deposited inside the mesoporous due to their strong coordination with thiourea based ligands (Mandal, Stavila, Rusakova, Ghosh, \& Whitmire, 2009). Based on the high electrocatalytic responses to BPA at Cu@TU-PMO/IL/GCE, a novel electrochemical sensor was developed for the detection of BPA. The designed sensor showed good performance with a wide linear range, a low detection limit, and had excellent reproducibility, stability and selectivity for the detection of BPA. The proposed sensorwas successfully applied in the detection of BPA in real plastic product and environmental samples.

\section{Experimental section}

\subsection{Material}

The (3-aminopropyl) triethoxysilane (APTES) $\geq 98 \%$, Pluronic P123 (Poly(ethylene glycol)-block-poly(propylene glycol)-block-poly(ethylene glycol, molecular weight 5800), bis-thiourea $\geq 98 \%, \mathrm{CuCl}_{2} \approx 100 \%$, Bisphenol A $\geq 99 \%$, 1-Butyl-3-methylimidazolium hexafluorophosphate $\geq 97 \%$ were purchased from Sigma-Aldrich and were used as received without any further purification. All the other chemicals used were analytical reagent grade. The test solutions of various metal cations and anions were prepared from the corresponding analytical grade metal salts and were diluted to the desired concentration. Double distilled water was used throughout the process.

\subsection{Apparatus}

Electrochemical analysis, such as cyclic voltammetry and differential pulse voltammetry, were carried out using Auto-Lab potentiostat-galvanostat (ECO Chemie, Utrecht, Netherlands) equipped with a PGSTAT 30 module and driven by GPES (ECO Chemie). A threeelectrode system, including a saturated $\mathrm{Ag} / \mathrm{AgCl}$ ( $\mathrm{KCl}$ saturated), was used as the reference electrode, a platinum wire as a counter electrode, and a bare GCE or modified GCE (Cu@TU-PMO) as a working electrode. The UHPLC system used consisted of two pumps of a platin blue P-1 solvent delivery system, a diode array detector (PDA-1) operated at $217 \mathrm{~nm}$, a column oven manager and an analytical column (Blue Orchid C18, $1.8 \mu \mathrm{m}, 50 \times 2 \mathrm{~mm}$ ), all from Knauer, Berlin, Germany. A mixture of water-acetonitrile $(60: 40 \mathrm{v} / \mathrm{v})$ at a flow rate of $1 \mathrm{~mL}$ min was used as the mobile phase. The column oven temperature was set at $40^{\circ} \mathrm{C}$. The crystallinity and the morphology of the prepared nanocomposites were evaluated using X-ray diffraction (XRD, D8-Advance Bruner), transmission electron microscopy (TEM) (Philips/FEI CM200), and SEM (Philips XL-30 ESEM with an accelerating voltage of $20 \mathrm{kV}$ ).

\subsection{Synthesis of 1,3-bis(3-(triethoxysilyl) propyl) thiourea (bis-thiourea) bridge}

The 1,3-bis(3-(triethoxysilyl) propyl) thiourea (bis-thiourea) bridge was prepared according to the procedure described in our earlier contribution report (Doustkhah et al., 2017). $\mathrm{CS}_{2}(2 \mathrm{mmol})$ was slowly added to the (3-aminopropyl) triethoxysilane (APTES) ( $4 \mathrm{mmol}$ ), and the mixture was stirred for $30 \mathrm{~min}$ at room temperature. Then, the reaction mixture was heated to $100{ }^{\circ} \mathrm{C}$ under an inert atmosphere and stirred for another $30 \mathrm{~min}$. The complete evolution of hydrogen sulfide gas in the reaction mixture was an indication that the reaction is completed. After that, the mixture was left to cool down at room temperature. A dark yellow liquid was finally obtained and was characterised using ${ }^{1} \mathrm{H}$ NMR and ${ }^{13} \mathrm{C}$ NMR.

\subsection{Synthesis of SBA-15 like TU-PMO}

The thiourea-bridged periodic mesoporous organosilica was synthesized according to our previously reported procedure (Doustkhah et al., 2017). Briefly, $2 \mathrm{~g}$ of P123 was dissolved in an aqueous solution of $\mathrm{HCl}(75 \mathrm{~mL}, 2 \mathrm{M})$ and stirred at ambient temperature, till the solution becomes clear. Afterwards, it was heated to $40{ }^{\circ} \mathrm{C}$ for $4 \mathrm{~h}$, followed by the dropwise addition of the abovementioned product bis-thiourea ( $2 \mathrm{mmol}$ ) and TEOS (16 mmol, $3.7 \mathrm{~mL}$ ). The resulting mixture was left to stir for 24 and then the reaction was stopped, followed by being aged for $24 \mathrm{~h}$ at $100{ }^{\circ} \mathrm{C}$. Finally, the resulting yellow solid was filtered and purified with EtOH using the Soxhlet extraction method for 3 days. The CHN analysis of TU-PMO revealed that $19 \mathrm{wt} \%$ organic loading was obtained. 


\subsection{Synthesis of Cu@TU-PMO}

An aqueous solution of dihydrate $\mathrm{CuCl}_{2}(0.17 \mathrm{~g})$ was dispersed in an ethanol solution $(20 \mathrm{~mL})$ containing the TU-PMO $(1 \mathrm{~g})$ and stirred at ambient temperature for $1 \mathrm{~h}$. The resulting solid was collected by filtration, washed copiously with ethanol, and dried under vacuum at $60{ }^{\circ} \mathrm{C}$. The product obtained was designated as Cu@TU-PMO. After synthesis of Cu@TU-PMO, its copper content was calculated to be 5.9 wt $\%$ according to AAS analysis.

\subsection{Preparation of $C u @ T U-P M O / G C E$}

Before modifying the glassy carbon electrode (GCE), it was thoroughly polished with alumina slurry $(0.3 \mu \mathrm{m}$ and $0.05 \mu \mathrm{m})$ on a polishing cloth for $3 \mathrm{~min}$. Then, it was sonicated sequentially in ethanol, and distilled water. For preparation of Cu@TU-PMO-IL/GCE, first 5 mg of Cu@TU-PMO and $20 \mu \mathrm{L}$ of the1-Butyl-3-methylimidazolium hexafluorophosphate (IL) was dispersed in $2.0 \mathrm{~mL}$ distilled water by ultrasonication and stirring for $1 \mathrm{~h}$ until a homogenous suspension was produced. Then, $5 \mu \mathrm{L}$ of the above suspensions was dropped on the surface of the glassy carbon electrode and allowed to dry for $30 \mathrm{~min}$ at ambient temperature. The other electrodes were modified using the same methodology.

\section{Result and discussion}

\subsection{Cu@TU-PMO characterization}

The synthesis of the SBA-15 like Cu@TU-PMO was accomplished in two steps. The thiourea based PMO with a 2D-hexagonal symmetry was first prepared following a co-condensation of TEOS and as-synthseized bis-thioure in the presence of P123 under acidic conditions, wherein the bis-thiourea was employed as thiourea precursors. Consideration the fact that, metal species can have good coordination with thiourea based ligands (Al-Kady, Gaber, Hussein, \& Ebeid, 2009), thereby $\mathrm{Cu}^{2+}$ species has been grafted inside the surface of TU-PMO through thiourea bridges.

The surface morphologies of Cu@TU-PMO was studied by both scanning electron microscopy (SEM) and transmission electron microscopy (TEM) (Fig. 1a-d). The SEM image of pure PMO (Fig. 1a) revealed the presence of an agglomerate rod-type structure with relatively uniform length. Besides, as can be seen from the TEM image (Fig. 1c), SBA15 exhibited the two-dimensional hexagonal arrays of long cylindrical pores structure and one-dimensional pore channel which is characteristic of mesoporous materials. However, after loading of $\mathrm{Cu}^{2+}$, as shown in Fig. 1b, no significant effect either on morphology or structure of the thiourea based PMO could be observed, and it can be said that overall particle morphology similar to TU-PMO was obtained. In addition, the TEM image, as shown in Fig. 1d, clearly displayed a long-range order and uniform channel structure along the pore axis. Besides, it was found that the Cu@TU-PMO has a uniform pore size with an average diameter of $6.8 \mathrm{~nm}$.

The compositional analysis of surface morphology and topology from TU-PMO and Cu@TU-SBA-15 like PMO is considered by EDX, as shown in Fig. 2(a, b). It confirmed that the elements $\mathrm{C}, \mathrm{O}, \mathrm{S}, \mathrm{N}$, and $\mathrm{Cu}$ are present in the given sample. The $\mathrm{N}_{2}$ adsorption-desorption isotherms record the TU-PMO and Cu@TU-PMO's textural properties, as shown in Fig. 2c, d. As could be seen, the samples display typical type-IV isotherm with a $\mathrm{H}_{1}$ hysteresis loop, which is characteristic of SBA-15 type mesoporous silica materials. The decline of the hysteresis loop and consequent decrease in surface area and pore volume of PMO maybe due to the deposition of $\mathrm{Cu}^{2+}$ on internal surface of the mesoporous channels. Hence, the BET surface area of Cu@TU-PMO was $283 \mathrm{~m}^{2} \mathrm{~g}^{-1}$, which is less than the TU-PMO $\left(390 \mathrm{~m}^{2} \mathrm{~g}^{-1}\right)$. Nevertheless, it is worth noting that the high surface area is preserved even though the loading of $\mathrm{Cu}^{2+}$ has occurred. Moreover, the average pore size was $6.8 \mathrm{~nm}$ for instead $2 \mathrm{~nm}$ for Cu-PMO using the BJH method (Fig. 2d).

\subsection{Electrochemical behaviors of BPA}

Typical cyclic voltammograms of GCE, Cu@TU-PMO /GCE and Cu@TU-PMO -IL/GCE in the absence and presence of $0.1 \mathrm{mM}$ BPA solution prepared in $0.1 \mathrm{M}$ PBS ( $\mathrm{pH}$ 7.0) are shown in curves a, b and c of Fig. 4a and b, respectively. As reported, no anodic peak current was observed for BPA oxidation at GCE electrode (Fig. 3b - curve a) that may

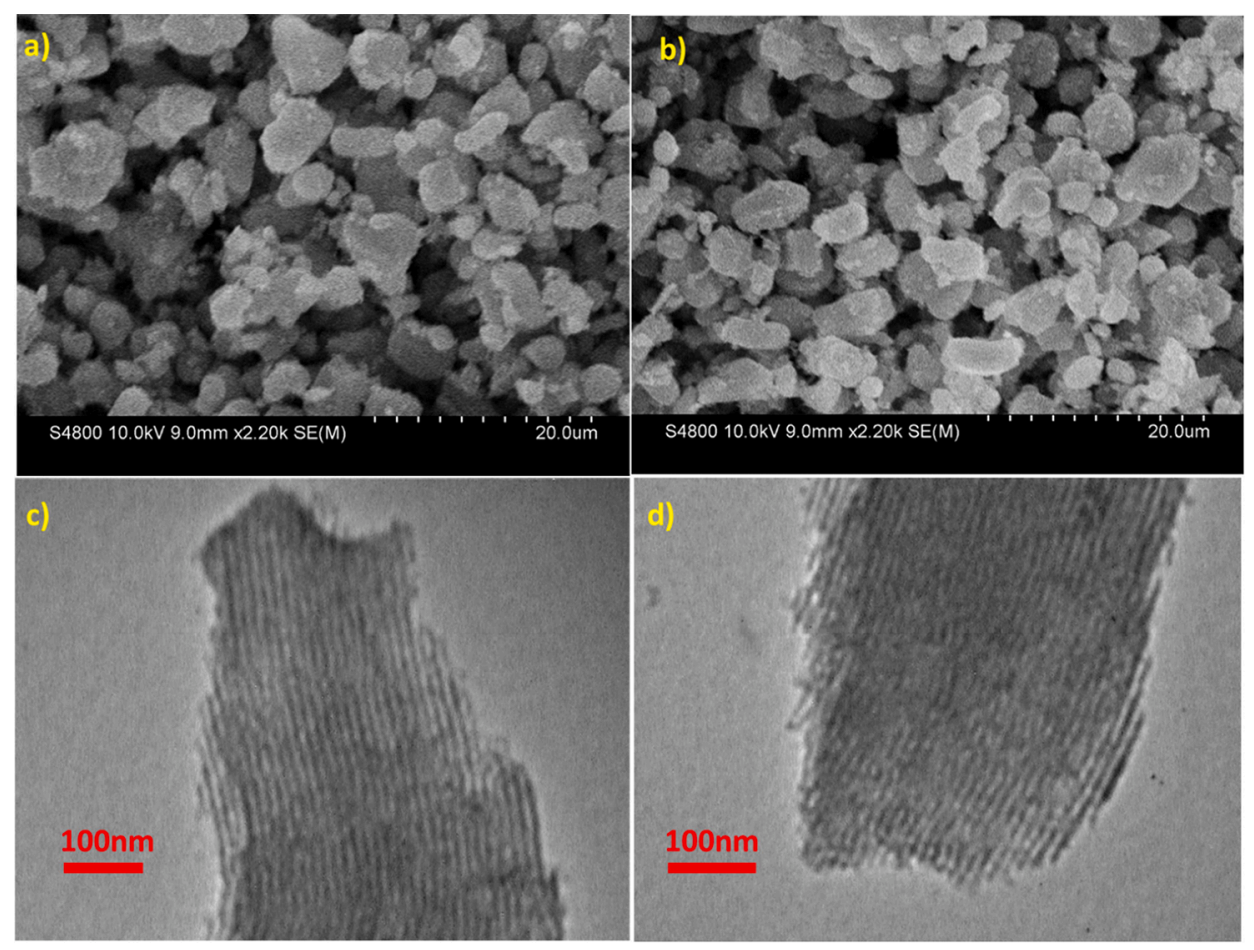

Fig. 1. (a, c) SEM and TEM image of TU-PMO; (b, d) SEM and TEM image of Cu@TU-PMO. 

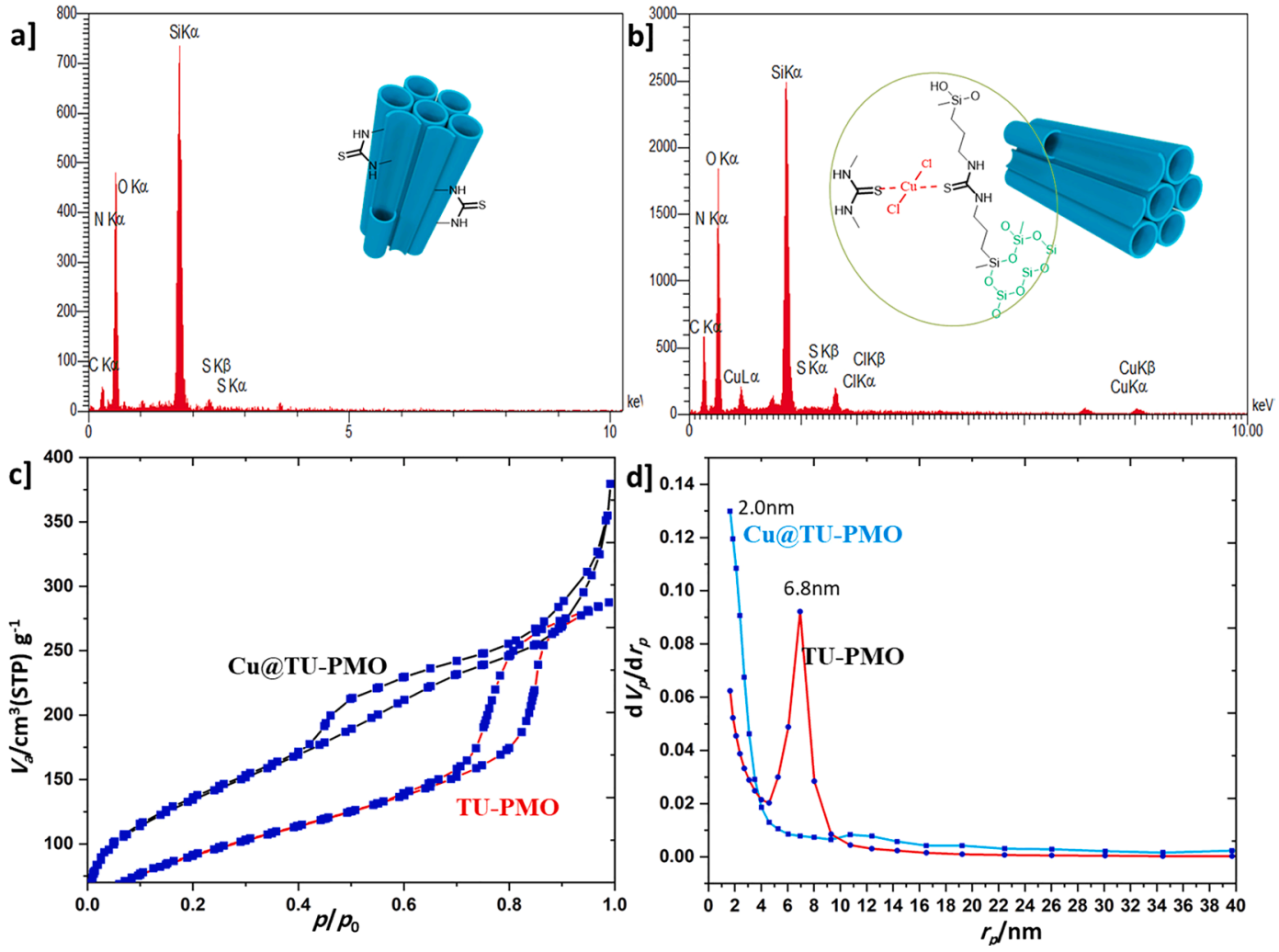

Fig. 2. The EDX spectra of (a) TU-PMO, (b) Cu@TU-PMO. (c) The $\mathrm{N}_{2}$ absorption-desorption isotherm and (d) pore-size distribution by BJH method for TU-PMO and Cu@TU-PMO.
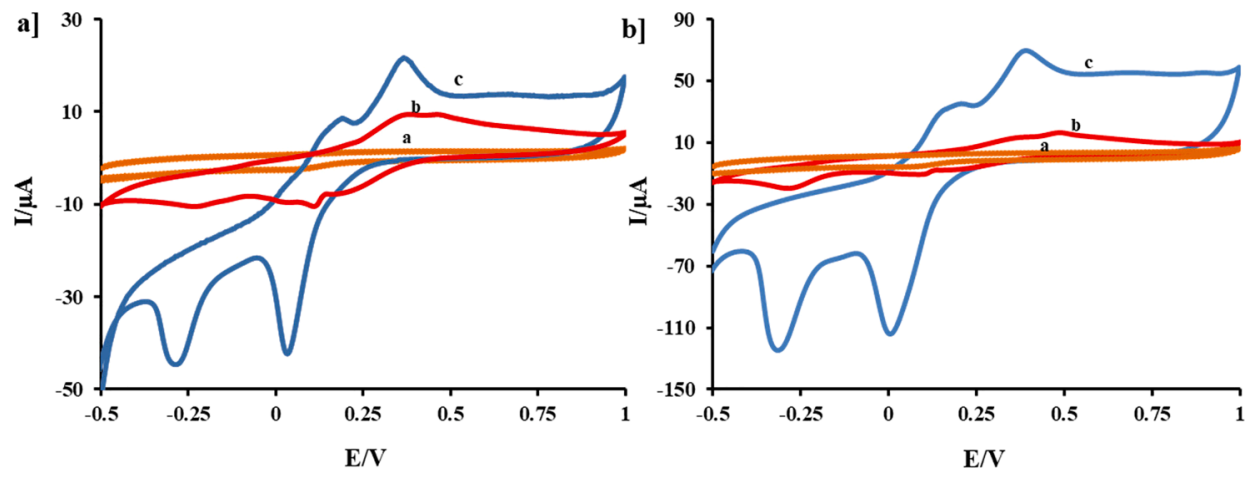

Fig. 3. CVs of GCE (a), Cu@TU-PMO /GCE (b) and Cu@TU-PMO /IL/GCE (c) in the absence (a) and presence (b) of $0.1 \mathrm{mM}$ BPA in $0.1 \mathrm{M}$ PBS (pH 7). Scan rate: $50 \mathrm{mVs}^{-1}$.

be due to the high overpotential associated with the oxidation process. Cu@TU-PMO/GCE and Cu@TU-PMO - IL/GCE in the absence of BPA two oxidation peaks were observed on using the modified electrode, this revealed the oxidation of $\mathrm{Cu}(0)$ to $\mathrm{Cu}(\mathrm{I})$ and $\mathrm{Cu}(\mathrm{I})$ to $\mathrm{Cu}(\mathrm{II})$ and two reduction peaks revealed reduction of $\mathrm{Cu}(\mathrm{II})$ to $\mathrm{Cu}(\mathrm{I})$ and $\mathrm{Cu}(\mathrm{I})$ to $\mathrm{Cu}(0)$ (Fig. 3a - curve b, c).

By applying the Cu@TU-PMO (Fig. 3b, curve b), the anodic peak current of PMO-Cu (II) was enhanced because of the presence of BPA and the peak potential was shifted toward more negative values due to the electrocatalytic activity of Cu (II). In contrast, Cu@TU-PMO -IL/GCE (Fig. $3 \mathrm{~b}$ - curve c) showed a higher and sharper oxidation peak response than the other electrodes due to the electrocatalytic properties of $\mathrm{Cu}$ (II) and the presence of IL. The fabricated sensor (Cu@TU-PMO - IL/GCE) displayed excellent properties such as high electrical conductivity and high electrocatalytic activity. It is important to highlight that the ionic liquid help to facilitate electron communication on the electrode surface.

\section{3. $p H$ studies}

The effect of $\mathrm{pH}$ on bisphenol A determination was carried out because the ionic state of BPA can be affected by the proton environment. Also, the $\mathrm{pH}$ analysis helps to determine the $\mathrm{pH}$ where BPA is most available for the electrochemical detection using Cu@TU-PMO/GCE. The results obtained in Fig. $4 \mathrm{a}$ and $\mathrm{b}$ revealed that there was an enhancement in the peak current signal as $\mathrm{pH}$ value increases from 3 to 7 in the detection of $0.1 \mathrm{mM}$ BPA. After this, a reduction in the peak current signal was observed. Hence, $\mathrm{pH} 7$ was used as the working $\mathrm{pH}$ for the electrochemical detection of BPA.

Furthermore, there was a cathodic shift in the anodic peak potential (Epa) as pH increased. As shown in Fig. 4c, the plot displayed a good linear relationship between the Epa and $\mathrm{pH}$, this suggests that protons 


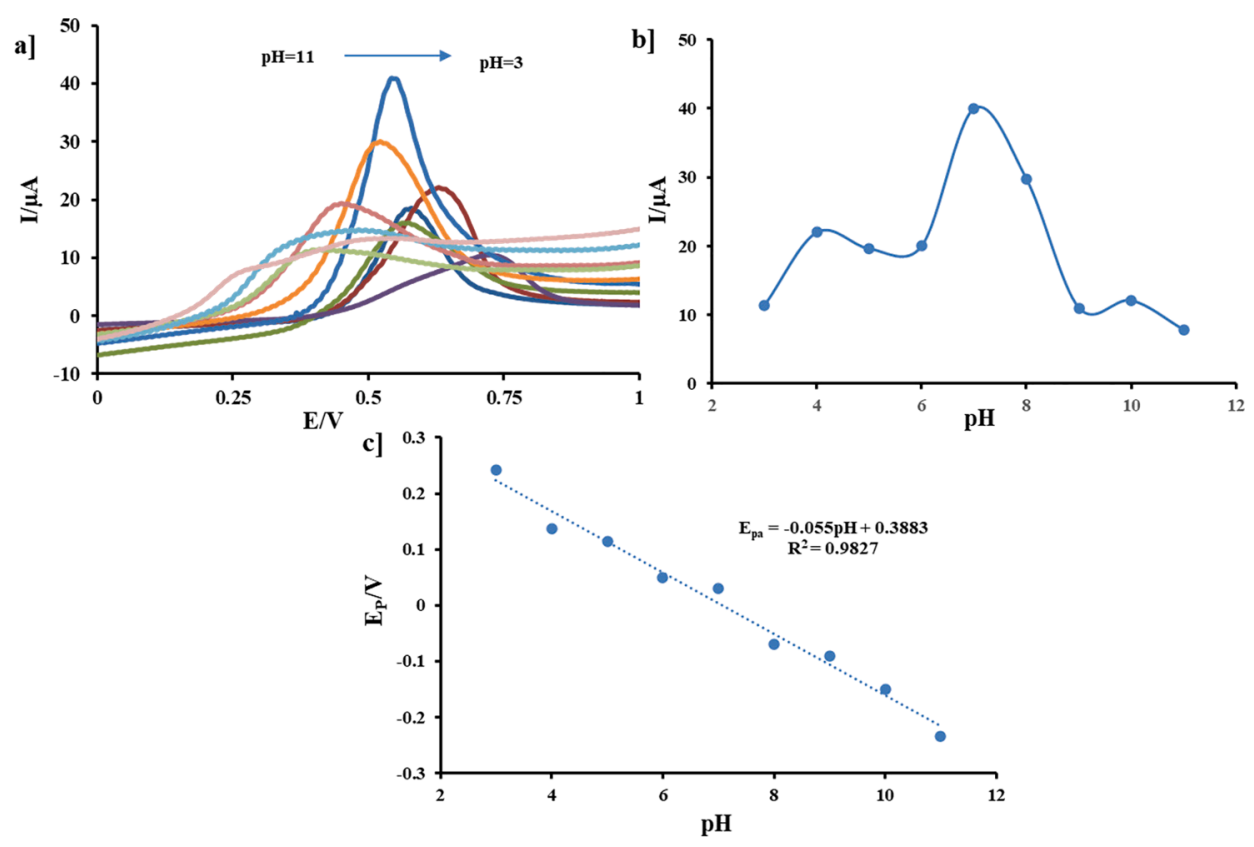

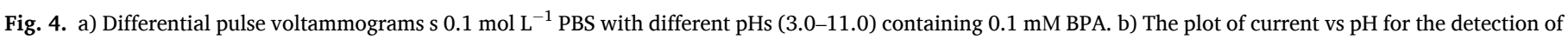
BPA. c) The plot of Ep vs $\mathrm{pH}$ for the detection of BPA.

played a pivotal role in the electrochemical detection of BPA. The regression equation obtained was Epa $=-0.055 \mathrm{pH}+0.3883$ $(\mathrm{R}=0.9827)$. This equation showed that the slope value of $(55 \mathrm{mV} / \mathrm{pH})$ was proximity with the theoretical value of $57.6 \mathrm{mV} / \mathrm{pH}$. This result established that there was an equal transfer of proton and electron transfer in the electrochemical process. According to obtained data, the mechanism suggested for electrochemical oxidation of BPA was depicted in the Scheme S1 in Supporting Information part (UlubayKarabiberoğlu, 2019).

\subsection{Scan rate studies}

The cyclic voltammetry was used to interrogate the effect of scan rates on the constructed electrode Cu@TU-PMO/GCE; the findings revealed that there was an enhancement in the oxidation peak current signal as the scan rate increases from $(10,20,30,60,80,90$, and $100 \mathrm{mV} / \mathrm{s}$ ), and the results were shown in Fig. S1a. This result confirmed that the electrochemical reaction of bisphenol A at the fabricated electrode is typical adsorption-controlled electrode process. The oxidation peak current gave a linear regression equation of $\mathrm{p}_{\mathrm{a}}=0.4868 \mathrm{v}+22.273$, and a correlation coefficient is $\mathrm{R}=0.9947$ (Fig. S1b).

\subsection{Analytical performance, reproducibility and stability measurement}

The electroanalytical determination of BPA using of the modified electrode (Cu@TU-PMO-IL/GCE) under optimal conditions carried out using differential pulse voltammetry (Fig. 5). The oxidation peak current increases as the concentration of BPA increases. The calibration plot constructed from the DPV response, illustrated in Fig. S1b, clearly shows two linear regions, from $0.05 \mu \mathrm{M}$ to $2 \mu \mathrm{M}$ and from $4 \mu \mathrm{M}$ to $500 \mu \mathrm{M}$ following the equations $\operatorname{Ip}_{\mathrm{a}}(\mu \mathrm{A})=3.84 \mathrm{c}(\mu \mathrm{M})+3.87(\mathrm{R}=0.97)$ and $\mathrm{Ip}_{\mathrm{a}}$ $(\mu \mathrm{A})=0.12 \mathrm{c}(\mu \mathrm{M})+13.55(\mathrm{R}=0.99)$, respectively. A detection limit of $1.5 \mathrm{nM}$ was obtained calculated as $\left(3 \times \mathrm{SD}_{\text {blank }}\right) /$ slope was $1.5 \mathrm{nM}$ and $(n=3)$. To investigate the linearity of sensor, based on statistical analysis of the various error sum squares and variance components from a linear calibration data were carried out from $4 \mu \mathrm{M}$ to $500 \mu \mathrm{M}$ following the equations $\operatorname{Ip}_{\mathrm{a}}(\mu \mathrm{A})=3.84 \mathrm{c}(\mu \mathrm{M})+3.87$ for three measurements.

The correlation coefficient ( $\mathrm{r}$ ) is commonly used for this purpose, and
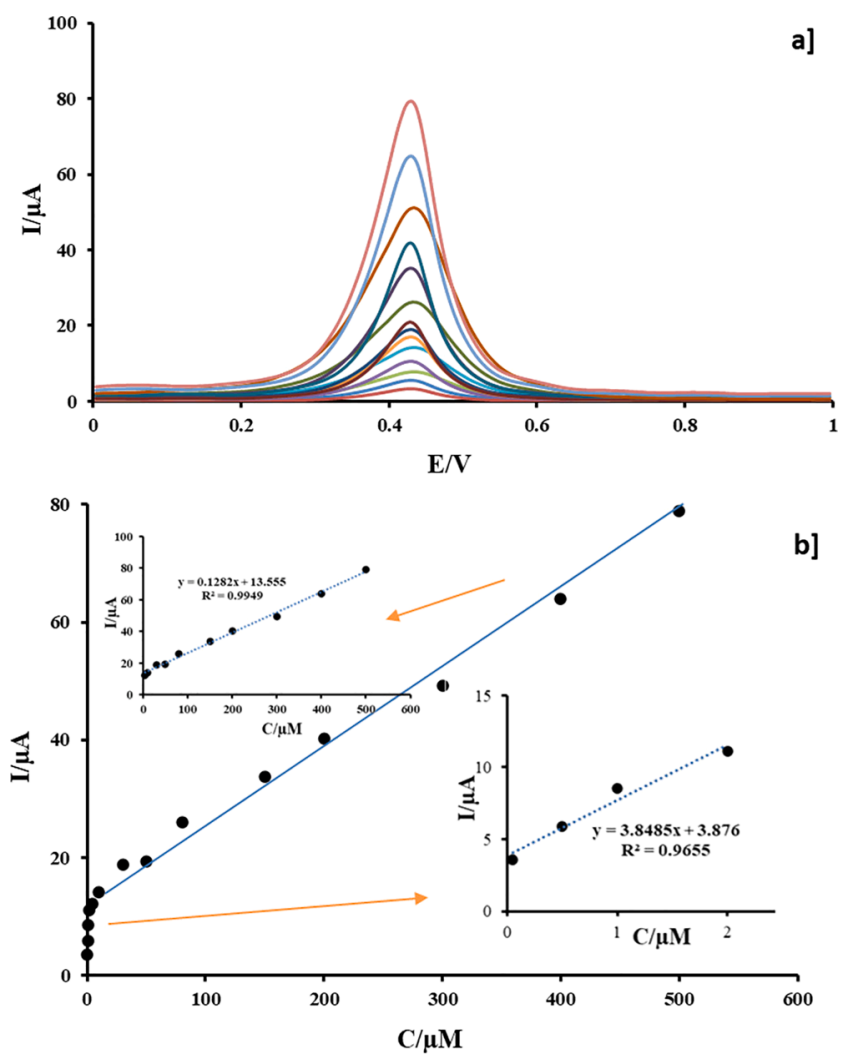

Fig. 5. (a) Differential pulse voltammograms of different concentrations of BPA from 0.05 to $500 \mu \mathrm{M}$, (b), and the linear dependence of peak currents and BPA concentrations.

curves with $r \geq 0.995$ are usually considered to be linear. Nevertheless, several investigators focussed on the fact that might not be a useful indicator of linearity, and other statistical tests or quality parameters have been suggested to ascertain the goodness of fit of the calibration curve (Jackson, 1966; Vankeerberghen \& Smeyers-Verbeke, 1992). In 
electronic Supporting information used the F-test as a reliable approach to check the linearity of calibration function. Table $\mathrm{S} 2$ were showed the DPV response of from $4 \mu \mathrm{M}$ to $500 \mu \mathrm{M}$ following the $\operatorname{Ip}_{\mathrm{a}}(\mu \mathrm{A})=0.12 \mathrm{c}$ $(\mu \mathrm{M})+13.55(\mathrm{R}=0.99)$ The value of $\mathrm{F}_{(\mathrm{I}-2) /(\mathrm{IJ}-\mathrm{I})}$ was obtained 1.56 that $\mathrm{F}$ calculated experimentally is less than the critical value of $F$ found in statistical tables (2045), generally at the $95 \%$ confidence level for 8 and 20 degrees of freedom in the numerator and denominator respectively. This method showed that there is a linearity in the reported data.

$\mathrm{F}_{(\mathrm{I}-2) /(\mathrm{IJ}-\mathrm{I})}=\frac{\sigma_{l o f}^{2}}{\sigma_{\varepsilon}^{2}}=\frac{2.50 \times 10^{-3}}{1.61^{-3}}=1.56$

1.56 (calculated) $<2.45$ (tabulated at the $95 \%$ with 8 and 20 degrees of freedom).

The detection limit and linear detection range obtained from Cu@TU-PMO-IL/GCE are superior or comparable to those reported previously in the literature, as depicted in Table S1 (Duan et al., 2018; Najafi, Khalilzadeh, \& Karimi-Maleh, 2014; Shi, Liang, Zhao, Liu, \& Tian, 2017; Su et al., 2017; UlubayKarabiberoğlu, 2019; Yin et al., 2011). The discussed results show that the proposed electrochemical sensor provides a sensitive determination for BPA.

To evaluate the modified electrodes' reproducibility, ten sensors (Cu@TU-PMO-IL/GCE) were prepared in the same way and were all used for the detection of $1 \mu \mathrm{M}$ BPA solution. The relative standard deviation of $4.3 \%(n=10)$ was obtained for the ten fabricated sensors. This result affirmed that the proposed sensor exhibited good reproducibility. In addition, a $1 \mu \mathrm{M}$ vanillin solution was determined successively for ten times with a Cu@TU-PMO-IL/GCE, and the RSD value was found to be $3.7 \%$, which affirmed the excellent repeatability of the fabricated sensor. The storage stability of the electrode was also examined. It was found that after stored in air for 2 weeks, the electrode retained $85 \%$ of its initial current response. Moreover, the influence of possible electrochemical active interferes such as organic compounds and metal ions were also evaluated by adding these species to BPA solution under optimal experimental conditions. The results indicated that 50 -fold amount of hydroxyphenol, dopamine, 4-nitrophenol, hydroxyphenol, ethanol and 100-fold concentration of $\mathrm{Mg}^{2+}, \mathrm{Al}^{3+}, \mathrm{Ca}^{2+}, \mathrm{Pb}^{2+}, \mathrm{SO}_{4}^{2-}, \mathrm{Cl}^{-}$ and $\mathrm{NO}_{3}^{-}$had little influence on the oxidation signal of bisphenol $\mathrm{A}$, and the change in the peak current was less than $5 \%$.

\subsection{Real sample analysis}

In order to evaluate the Cu@TU-PMO-IL/GCE performance for practical applications, the sensor was applied to detect BPA in PVC food packages, PC baby bottles, and PC water bottles. All samples were obtained from the local market. The samples collected were simply centrifuged to remove impurities. The food packages, PC baby bottles, and PC water bottles were first pre-cleaned, dried and cut into small pieces, respectively. Then $1.0 \mathrm{~g}$ of plastic samples (PC baby bottles and water bottles, or poly (vinyl chloride) (PVC) food packages) was first soaked in a flask containing $100 \mathrm{~mL}$ of doubly distilled water for $60 \mathrm{~min}$ at $70{ }^{\circ} \mathrm{C}$ and cooled at room temperature. After cooling, the water-leach liquor sample was filtered and collected. A standard addition method was used to evaluate the analytical performance of the sensor. The designed sensors were successfully applied to the determination of BPA in food storage container and mineral water and baby bottles samples with different brand with SWV technique were compared with the HPLC technique. The statistical comparison of SWV analysis results with HPLC analysis results was achieved using the $t$-test and F-test. It can be concluded from Table 1 that there is no significant difference between the results obtained by the two methods for $\mathrm{P}>0.05$. as in all cases, the calculated $\mathrm{t}$-values and F-values are lower than the $t$-value and F-value of 2.92 and 19 expected at $\mathrm{P}=0.05$ and $\mathrm{n}=3$. The official method showed that there is no significant difference between the proposed and reported methods as indicated from the F-test and $t$-test values. In addition, the recoveries of BPA achieved from the proposed sensor were in the range of $93.86-108.66 \%$, and the relative standard deviation (RSD) was found ranging from $1.38 \%$ to $4.29 \%$. This satisfactory result indicated the well accuracy and reliability of the fabricated Cu@TU-

Table 1

Determination of BPA in different samples.

\begin{tabular}{|c|c|c|c|c|c|c|c|}
\hline \multirow[t]{2}{*}{ Sample } & \multirow[t]{2}{*}{ BRAND } & \multirow[t]{2}{*}{ Added $(\mu \mathrm{m})$} & \multicolumn{2}{|c|}{ Founded $^{\mathrm{a}}(\mu \mathrm{m})+\mathrm{SD}^{\mathrm{b}}$} & \multirow[t]{2}{*}{$\mathrm{t}$ calculated } & \multirow[t]{2}{*}{ F calculated } & \multirow[t]{2}{*}{ Recovery } \\
\hline & & & Sensor & HPLC & & & \\
\hline \multirow[t]{6}{*}{ Mineral water bottles } & \multirow[t]{2}{*}{$\mathrm{A} 1$} & 0 & $18.42 \pm 0.92$ & $19.55 \pm 1.18$ & 1.23 & 1.64 & 93.86 \\
\hline & & 5 & $25.35 \pm 1.34$ & $24.48 \pm 1.76$ & 0.43 & 1.72 & 103.43 \\
\hline & \multirow[t]{2}{*}{ A2 } & 0 & $22.62 \pm 0.74$ & $21.89 \pm 1.16$ & 0.94 & 2.45 & 103.22 \\
\hline & & 5 & $27.69 \pm 0.56$ & $27.44 \pm 0.85$ & 0.59 & 2.30 & 100.90 \\
\hline & \multirow[t]{2}{*}{ A3 } & 0 & $35.12 \pm 1.54$ & $36.26 \pm 2.35$ & 0.35 & 2.32 & 96.75 \\
\hline & & 5 & $40.71 \pm 0.89$ & $41.67 \pm 1.31$ & 0.93 & 2.16 & 97.64 \\
\hline \multirow[t]{6}{*}{ Baby bottles } & \multirow[t]{2}{*}{ B1 } & 0 & $7.12 \pm 1.25$ & $6.89 \pm 2.14$ & 0.33 & 2.93 & 103.23 \\
\hline & & 5 & $12.65 \pm 2.68$ & $13.15 \pm 3.22$ & 0.12 & 1.44 & 96.04 \\
\hline & \multirow[t]{2}{*}{ B2 } & 0 & $10.91 \pm 1.36$ & $11.67 \pm 2.18$ & 0.28 & 2.56 & 98.53 \\
\hline & & 5 & $15.82 \pm 0.73$ & $14.97 \pm 1.04$ & 1.28 & 2.09 & 105.37 \\
\hline & \multirow[t]{2}{*}{ B3 } & 0 & $12.24 \pm 0.81$ & $11.18 \pm 0.92$ & 1.72 & 1.29 & 108.66 \\
\hline & & 5 & $17.38 \pm 1.28$ & $18.25 \pm 1.65$ & 0.48 & 1.66 & 94.99 \\
\hline \multirow[t]{6}{*}{ Tuna fish cans } & \multirow[t]{2}{*}{$\mathrm{C} 1$} & 0 & $26.42 \pm 2.62$ & $27.95 \pm 4.32$ & 0.14 & 2.71 & 94.20 \\
\hline & & 5 & $31.42 \pm 1.39$ & $32.74 \pm 2.15$ & 0.49 & 2.39 & 95.79 \\
\hline & \multirow[t]{2}{*}{$\mathrm{C} 2$} & 0 & $29.42 \pm 0.67$ & $30.17 \pm 0.97$ & 1.32 & 2.10 & 97.45 \\
\hline & & 5 & $34.42 \pm 1.95$ & $33.85 \pm 2.48$ & 0.14 & 1.61 & 101.65 \\
\hline & \multirow[t]{2}{*}{$\mathrm{C} 3$} & 0 & $43.87 \pm 1.56$ & $44.82 \pm 2.19$ & 0.32 & 1.97 & 97.83 \\
\hline & & 5 & $48.18 \pm 0.93$ & $49.05 \pm 1.32$ & 0.76 & 2.01 & 98.19 \\
\hline \multirow[t]{6}{*}{ Tomato paste cans } & \multirow[t]{2}{*}{ D1 } & 0 & $23.11 \pm 1.74$ & $22.52 \pm 2.21$ & 0.18 & 1.61 & 102.55 \\
\hline & & 5 & $29.58 \pm 1.32$ & $28.12 \pm 1.71$ & 0.76 & 1.67 & 104.93 \\
\hline & \multirow[t]{2}{*}{ D2 } & 0 & $27.41 \pm 0.29$ & $28.25 \pm 0.52$ & 3.44 & 1.46 & 97.66 \\
\hline & & 5 & $32.35 \pm 0.81$ & $31.62 \pm 1.29$ & 0.77 & 2.53 & 102.25 \\
\hline & \multirow[t]{2}{*}{ D3 } & 0 & $31.42 \pm 1.95$ & $32.49 \pm 2.85$ & 0.21 & 2.13 & 96.59 \\
\hline & & 5 & $36.85 \pm 0.74$ & $37.55 \pm 1.42$ & 0.86 & 1.73 & 98.10 \\
\hline
\end{tabular}

$t$-value at $\mathrm{P}=0.02$ and 2 degrees of freedom is 2.92 .

F-value at $\mathrm{P}=0.05$ and $2 / 2$ degrees of freedom is 19 .

a Average of three measurements.

b Shows the standard deviation $(\mathrm{n}=3)$. 
PMO-IL/GCE; which can make it suitable for the determination of BPA in some practical samples.

\section{Conclusions}

A novel Cu@TU-PMO-IL modified electrode was fabricated for the analysis of BPA. This electrode gives better electrocatalytic activity towards the oxidation of BPA. The reasons can be attributed to the catalytic activity of copper in catalyst structure and conductivity of IL. The lower detection limit and linear range were achieved on this modified electrode compared to reports documented in the literature. Additionally, the fabricated BPA sensor showed good reproducibility and reusability.

The modified electrode had a detection limit lower than the permissible limit for the analyte in water demonstrating its analytical merit. The applicability of the fabricated electrode was revealed by its application in different matrixes. The results obtained from HPLC technique were in concord with this method thus substantiating its analytical integrity. The developed sensor is thus opened a new opportunity for detecting the BPA in the environmental samples.

\section{CRediT authorship contribution statement}

Aziz Eftekhari: Supervision, Funding acquisition. Maryam Dalili: Data curation, Investigation, Methodology. Ziba Karimi: Formal analysis. Shamila Rouhani: Formal analysis, Writing - review \& editing. Amir Hasanzadeh: Supervision. Sadegh Rostamnia: Supervision. Samad Khaksar: editing. Azeez Olayiwola Idris: Writing - review \& editing. Hassan Karimi-Maleh: Supervision. Mehmet Lütfi Yola: editing. Titus A.M. Msagati: editing.

\section{Declaration of Competing Interest}

The authors declare that they have no known competing financial interests or personal relationships that could have appeared to influence the work reported in this paper.

\section{Acknowledgment}

The authors would like to acknowledge the financial support of Maragheh University of Medical Sciences for this research under grant number IR.MARAGHEHPHC.REC.1398.021.

\section{Appendix A. Supplementary data}

Supplementary data to this article can be found online at https://doi. org/10.1016/j.foodchem.2021.129763.

\section{References}

Al-Kady, A. S., Gaber, M., Hussein, M. M., \& Ebeid, E. Z. M. (2009). Fluorescence enhancement of coumarin thiourea derivatives by $\mathrm{Hg} 2+, \mathrm{Ag}+$ and silver nanoparticles. Journal of Physical Chemistry A, 113(34), 9474-9484. https://doi.org/ 10.1021/jp905566z.

Apodaca, D. C., Pernites, R. B., Ponnapati, R., Del Mundo, F. R., \& Advincula, R. C. (2011). Electropolymerized molecularly imprinted polymer film: EIS sensing of bisphenol A. Macromolecules, 44(17), 6669-6682. https://doi.org/10.1021/ ma2010525.

Ben Messaoud, N., Ghica, M. E., Dridi, C., Ben Ali, M., \& Brett, C. M. A. (2017). Electrochemical sensor based on multiwalled carbon nanotube and gold nanoparticle modified electrode for the sensitive detection of bisphenol A. Sensors and Actuators, B: Chemical, 253, 513-522. https://doi.org/10.1016/j.snb.2017.06.160.

Chandra, D., Das, S. K., \& Bhaumik, A. (2010). A fluorophore grafted 2D-hexagonal mesoporous organosilica: Excellent ion-exchanger for the removal of heavy metal ions from wastewater. Microporous and Mesoporous Materials, 128(1-3), 34-40. https://doi.org/10.1016/j.micromeso.2009.07.024.

Chang, C. M., Chou, C. C., \& Lee, M. R. (2005). Determining leaching of bisphenol A from plastic containers by solid-phase microextraction and gas chromatography-mass spectrometry. Analytica Chimica Acta, 539(1-2), 41-47. https://doi.org/10.1016/j. aca.2005.03.051.
Chen, Z., Zuo, X., He, D., Ding, S., Xu, F., Yang, H., ... Ying, C. (2017). Long-term exposure to a 'safe' dose of bisphenol A reduced protein acetylation in adult rat testes. Scientific Reports, 7(December 2016), 1-9. https://doi.org/10.1038/ srep40337.

Darabi, R., \& Shabani-Nooshabadi, M. (2021). $\mathrm{NiFe}_{2} \mathrm{O}_{4}$-rGO/ionic liquid modified carbon paste electrode: An amplified electrochemical sensitive sensor for determination of Sunset Yellow in the presence of Tartrazine and Allura Red. Food Chemistry, 339 (August 2020), 127841. https://doi.org/10.1016/j.foodchem.2020.127841.

Doustkhah, E., Rostamnia, S., Imura, M., Ide, Y., Mohammadi, S., Hyland, C. J. T., Yamauchi, Y. (2017). Thiourea bridged periodic mesoporous organosilica with ultrasmall Pd nanoparticles for coupling reactions. RSC Advances, 7(89), 56306-56310. https://doi.org/10.1039/C7RA11711F.

Duan, Y., Li, S., Lei, S., Qiao, J., Zou, L., \& Ye, B. (2018). Highly sensitive determination of bisphenol A based on MoCuSe nanoparticles decorated reduced graphene oxide modified electrode. Journal of Electroanalytical Chemistry, 827, 137-144. https://doi. org/10.1016/j.jelechem.2018.08.011.

Esquivel, D., Van Der Voort, P., \& Romero-Salguero, F. J. (2014). Designing advanced functional periodic mesoporous organosilicas for biomedical applications. AIMS Materials Science, 1(1), 70-86. https://doi.org/10.3934/matersci.2014.1.70.

Geens, T., Aerts, D., Berthot, C., Bourguignon, J. P., Goeyens, L., Lecomte, P., .. Covaci, A. (2012). A review of dietary and non-dietary exposure to bisphenol-A. Food and Chemical Toxicology, 50(10), 3725-3740. https://doi.org/10.1016/j. fct.2012.07.059.

Hengstler, J. G., Foth, H., Gebel, T., Kramer, P. J., Lilienblum, W., Schweinfurth, H., .. Gundert-Remy, U. (2011). Critical evaluation of key evidence on the human health hazards of exposure to bisphenol A. Critical Reviews in Toxicology, 41(4), 263-291. https://doi.org/10.3109/10408444.2011.558487.

Jackson, J. E. (1966). The statistical analysis of experimental data. Technometrics, 8(1), 197-199. https://doi.org/10.1080/00401706.1966.10490337.

Karimi-Maleh, H., Alizadeh, M., Orooji, Y., Karimi, F., Baghayeri, M., Rouhi, J., ... Gupta, V. K. (2021). Guanine-based DNA biosensor amplified with Pt/SWCNTs nanocomposite as analytical tool for nanomolar determination of daunorubicin as an anticancer drug: A docking/experimental investigation. Industrial \& Engineering Chemistry Research, 60(2), 816-823.

Karimi-Maleh, H., Yola, M. L., Atar, N., Orooji, Y., Karimi, F., Senthil Kumar, P., Baghayeri, M. (2021). A novel detection method for organophosphorus insecticide fenamiphos: Molecularly imprinted electrochemical sensor based on core-shell $\mathrm{Co}_{3} \mathrm{O}_{4} @$ MOF-74 Nanocomposite. Journal of Colloid and Interface Science, 592, 174-185.

Kim, Y., Jeon, J. B., \& Chang, J. Y. (2012). CdSe quantum dot-encapsulated molecularly imprinted mesoporous silica particles for fluorescent sensing of bisphenol A. Journal of Materials Chemistry, 22(45), 24075-24080. https://doi.org/10.1039/c2jm34798a.

Krishnendu, S., Sarit, S. A., Chaekyu, K., Xiaoning, L., \& Vincent, M. R. (2014). Gold nanoparticles in chemical and biological sensing. Chemical Reviews, 112(5), 2739-2779. https://doi.org/10.1021/cr2001178.Gold.

Maiolini, E., Ferri, E., Pitasi, A. L., Montoya, A., Di Giovanni, M., Errani, E., \& Girotti, S. (2014). Bisphenol A determination in baby bottles by chemiluminescence enzymelinked immunosorbent assay, lateral flow immunoassay and liquid chromatography tandem mass spectrometry. Analyst, 139(1), 318-324. https://doi.org/10.1039/ c3an00552f.

Mandal, T., Stavila, V., Rusakova, I., Ghosh, S., \& Whitmire, K. H. (2009). Molecular precursors for cds nanoparticles: Synthesis and characterization of carboxylate Thiourea or - Tcadmium complexes and their decomposition. Chemistry of Materials, 21(23), 5617-5626. https://doi.org/10.1021/cm902230u.

Moaser, A. G., Ahadi, A., Rouhani, S., Mamba, B. B., Msagati, T. A. M., Rostamnia, S., Shokouhimehr, M. (2020). Curbed of molybdenum oxido-diperoxido complex on ionic liquid body of mesoporous Bipy-PMO-IL as a promising catalyst for selective sulfide oxidation. Journal of Molecular Liquids, 312(Vi), 113388. https://doi.org/ 10.1016/j.molliq.2020.113388.

Morante-Zarcero, S., Pérez-Quintanilla, D., \& Sierra, I. (2015). A disposable electrochemical sensor based on bifunctional periodic mesoporous organosilica for the determination of lead in drinking waters. Journal of Solid State Electrochemistry, 19(7), 2117-2127. https://doi.org/10.1007/s10008-015-2889-5.

Murugananthan, M., Yoshihara, S., Rakuma, T., \& Shirakashi, T. (2008). Mineralization of bisphenol A (BPA) by anodic oxidation with boron-doped diamond (BDD) electrode. Journal of Hazardous Materials, 154(1-3), 213-220. https://doi.org/ 10.1016/j.jhazmat.2007.10.011.

Najafi, M., Khalilzadeh, M. A., \& Karimi-Maleh, H. (2014). A new strategy for determination of bisphenol A in the presence of Sudan i using a ZnO/CNTs/ionic liquid paste electrode in food samples. Food Chemistry, 158, 125-131. https://doi. org/10.1016/j.foodchem.2014.02.082.

Nerín, C., Philo, M. R., Salafranca, J., \& Castle, L. (2002). Determination of bisphenoltype contaminants from food packaging materials in aqueous foods by solid-phase microextraction-high-performance liquid chromatography. Journal of Chromatography A, 963(1-2), 375-380. https://doi.org/10.1016/S0021-9673(02) 00554-X.

Ragavan, K. V., \& Rastogi, N. K. (2016). Graphene-copper oxide nanocomposite with intrinsic peroxidase activity for enhancement of chemiluminescence signals and its application for detection of bisphenol-A. Sensors and Actuators, B: Chemical, 229, 570-580. https://doi.org/10.1016/j.snb.2016.02.017.

Rosenfeld, C. S. (2017). Neuroendocrine disruption in animal models due to exposure to bisphenol A analogues. Frontiers in Neuroendocrinology, 47(August), 123-133. https://doi.org/10.1016/j.yfrne.2017.08.001.

Samiey, B., Cheng, C. H., \& Wu, J. (2014). Organic-inorganic hybrid polymers as adsorbents for removal of heavy metal ions from solutions: A review. Materials, 7(2), 673-726. https://doi.org/10.3390/ma7020673. 
Shi, R., Liang, J., Zhao, Z., Liu, A., \& Tian, Y. (2017). An electrochemical bisphenol A sensor based on one step electrochemical reduction of cuprous oxide wrapped graphene oxide nanoparticles modified electrode. Talanta, 169(December 2016), 37-43. https://doi.org/10.1016/j.talanta.2017.03.042.

Su, B., Shao, H., Li, N., Chen, X., Cai, Z., \& Chen, X. (2017). A sensitive bisphenol A voltammetric sensor relying on AuPd nanoparticles/graphene composites modified glassy carbon electrode. Talanta, 166(December 2016), 126-132. https://doi.org/ 10.1016/j.talanta.2017.01.049.

Tahernejad-Javazmi, F., Shabani-Nooshabadi, M., \& Karimi-Maleh, H. (2019). 3D reduced graphene oxide/ $\mathrm{FeNi}_{3}$-ionic liquid nanocomposite modified sensor; an electrical synergic effect for development of tert-butylhydroquinone and folic acid sensor. Composites Part B: Engineering, 172(May), 666-670. https://doi.org/10.1016/ j.compositesb.2019.05.065.

Tian, C., Chen, D., Lu, N., Li, Y., Cui, R., Han, Z., \& Zhang, G. (2018). Electrochemical bisphenol A sensor based on nanoporous PtFe alloy and graphene modified glassy carbon electrode. Journal of Electroanalytical Chemistry, 830-831, 27-33. https://doi. org/10.1016/j.jelechem.2018.10.023.

UlubayKarabiberoğlu, Ş. (2019). Sensitive voltammetric determination of bisphenol A based on a glassy carbon electrode modified with copper oxide-zinc oxide decorated on graphene oxide. Electroanalysis, 31(1), 91-102. https://doi.org/10.1002/ elan.201800415.
Vandenberg, L. N., Maffini, M. V., Sonnenschein, C., Rubin, B. S., \& Soto, A. M. (2009). Bisphenol-A and the great divide: A review of controversies in the field of endocrine disruption. Endocrine Reviews, 30(1), 75-95. https://doi.org/10.1210/er.2008-0021.

Vankeerberghen, P., \& Smeyers-Verbeke, J. (1992). The quality coefficient as a tool in decisions about the quality of calibration in graphite furnace atomic absorption spectrometry. Chemometrics and Intelligent Laboratory Systems, 15(2-3), 195-202. https://doi.org/10.1016/0169-7439(92)85009-R.

Wu, D., Tan, W., Li, H., Lei, Z., Deng, L., \& Kong, Y. (2019). A facile route to prepare functional mesoporous organosilica spheres with electroactive units for chiral recognition of amino acids. Analyst, 144(2), 543-549. https://doi.org/10.1039/ c8an01519h.

Xin, X., Sun, S., Li, H., Wang, M., \& Jia, R. (2015). Electrochemical bisphenol A sensor based on core-shell multiwalled carbon nanotubes/graphene oxide nanoribbons. Sensors and Actuators, B: Chemical, 209, 275-280. https://doi.org/10.1016/j. snb.2014.11.128.

Yin, H., Cui, L., Chen, Q., Shi, W., Ai, S., Zhu, L., \& Lu, L. (2011). Amperometric determination of bisphenol A in milk using PAMAM-Fe3O4 modified glassy carbon electrode. Food Chemistry, 125(3), 1097-1103. https://doi.org/10.1016/j foodchem.2010.09.098. 